\title{
Exigências de Mantença e de Ganho de Proteína e de Energia em Codornas Japonesas (Coturnix coturnix japonica) na Fase de 1 a 12 Dias de Idade ${ }^{1}$
}

\author{
José Humberto Vilar da Silva ${ }^{2}$, Marinalva Barbosa da Silva ${ }^{3}$, José Jordão Filho ${ }^{3}$, Edson Lindolfo \\ da Silva ${ }^{3}$, Iremar Silva Andrade ${ }^{4}$, Djair Alves de Melo ${ }^{4}$, Marcelo Luís Gomes Ribeiro ${ }^{2}, 5$, Maria do \\ Rosário de Fontes Rocha ${ }^{6}$, Fernando Guilherme Perazzo Costa ${ }^{7}$, Wilson Moreira Dutra Júnior ${ }^{8}$
}

RESUMO - Este experimento foi conduzido com o objetivo de estimar as exigências em proteína e energia para mantença e ganho em 384 fêmeas de codornas japonesas de 1 a 12 dias de idade. Utilizou-se um delineamento inteiramente ao acaso com quatro tratamentos, composto por seis repetições de dez aves. Os tratamentos foram: $\mathrm{T}_{1}=$ dieta basal (DB) com $28 \%$ de proteína bruta $(\mathrm{PB})$ e $2.900 \mathrm{kcal}$ de energia metabolizável aparente corrigida pelo balanço de nitrogênio (EMAn) fornecida à vontade; $\mathrm{T}_{2}=80 \% ; \mathrm{T}_{3}=60 \% ; \mathrm{e} \mathrm{T}_{4}=40 \%$ do nível de oferta do $\mathrm{T}_{1}$ (próximo à mantença). No início da fase experimental, quatro grupos (referência) de 15 codornas foram abatidos por deslocamento cervical, sem perdas de penas e de sangue. Para as estimativas das exigências de ganho, doze grupos de 15 codornas foram criados paralelamente, alimentados à vontade, sendo abatidos quatro grupos no $4 \stackrel{\mathrm{o}}{,}, 8 \underline{\mathrm{o}}$ e $12^{2} \underline{\mathrm{o}}$ dia. As aves de todas as parcelas também foram abatidas no 12 o dia, para estimar as exigências de mantença. As equações de predição para estimar as exigências diárias de mantença e de ganho em proteína e energia em codornas japonesas na fase de 1 a 12 dias foram, respectivamente: $\mathrm{PB}(\mathrm{g} / \mathrm{d})=2,845 . \mathrm{P}^{0,75}+0,461 . \mathrm{G}$ e EMAn $(\mathrm{kcal} / \mathrm{d})=77,07 . \mathrm{P}^{0,75}+4,64 . \mathrm{G}$, em que PB é a exigência de proteína bruta; P, o peso vivo (kg); G, o ganho de peso (kg); e EMAn, a energia metabolizável aparente corrigida pelo balanço de nitrogênio (kcal).

Palavras-chave: deposição de nutrientes, energia, modelagem, proteína

\section{Maintenance and Weight Gain of Crude Protein and Metabolizable Energy Requirements of Japanese Quails (Coturnix coturnix japonica) from 1 to 12 Days of Age}

\begin{abstract}
This experiment was carried out to estimate the crude protein and metabolizable energy requirements for maintenance and gain of 384 females of Japanese quails from 1 to 12 days of age. A completely randomized design with four treatments, with six replicates of ten birds each, was used. The treatments were: $\mathrm{T}_{1}=$ basal diet (BD) with $28 \% \mathrm{CP}$ and 2,900 kcal AMEn ad libitum; $\mathrm{T}_{2}=80 \% ; \mathrm{T}_{3}=60 \%$ and $\mathrm{T}_{4}=40 \%$ of ad libitum (close to maintenance). In the beginning of the experimental phase, four groups of 15 quails was slaughtered by cervical displacement. Gain requirements were obtained from 12 groups of 15 quails, that were separately reared and fed ad libitum. Therefore, four groups of fifteen birds were slaughtered at 4, 8 and 12 days of age. In the final of the experiment, all birds from pens were slaughtered to estimate maintenance requirements by the comparative slaughter methodology. The prediction equations to estimate daily CP and AMEn requirements of maintenance and gain of Japanese quails from 1 to 12 days of age were: $\mathrm{CP}$ $(\mathrm{g} / \mathrm{d})=2.845 . \mathrm{W}^{.75}+0.461 . \mathrm{G}$ and AMEn $(\mathrm{kcal} / \mathrm{d})=77.07 . \mathrm{P}^{0.75}+4.64 . \mathrm{G}$, where $\mathrm{CP}$ is crude protein, $\mathrm{W}$ is live weight $(\mathrm{kg}), \mathrm{G}$ is weight gain and AMEn is apparent metabolizable energy nitrogen-corrected (kcal).
\end{abstract}

Key Words: energy, modeling, nutrient accretion, crude protein

\section{Introdução}

Apesar de ainda não existirem relatos sobre a seleção de linhagens de codornas de alto desempenho comercial (Hoffmann, 1988), várias experiências de seleção para ganho de peso, qualidade da carcaça, produção e peso dos ovos, entre outras características, têm sido descritas (Cheng, 2002). Com o surgimento de programas de melhoramento genético de codornas no Brasil (Martins, 2002), cresce a importância de estudos para o estabelecimento das exigências nutricionais destas aves.

\footnotetext{
1 Parte da Dissertação de Mestrado do segundo autor. Bolsista da CAPES.

2 Professor do Departamento de Agropecuária - CFT/UFPB. Bananeiras, PB - CEP: 58.220-000 (jvilar@iwpb.com.br)

3 Aluno do curso de Mestrado em Zootecnia-CCA/UFPB. Areia, PB - CEP: 58.360-000.

${ }^{4}$ Aluno de Graduação em Licenciatura em Técnicas Agropecuárias - DAP/CFT/UFPB. Bolsista PIBIC - CNPq/UFPB.

5 Aluno de Doutorado Integrado em Zootecnia - UFPB-UFRPE-UFC.

6 Aluna de Licenciatura em Técnicas Agropecuárias - DAP/CFT/UFPB. Bolsista Voluntária do Aviário.

${ }^{7}$ Professor do DZ/CCA/UFPB - Areia, PB - CEP: 58.360-000 (fperazzo@cca.ufpb.br).

8 Professor do DZ/UFRPE - Recife, PE (dutrajr@ufrpe.br).
} 
A curva de crescimento de um plantel de 537 mil codornas japonesas de 1 a 42 dias de idade foi mostrada por Oliveira (2002). Observou-se acentuada taxa de crescimento no final da primeira semana e declínio na metade da quarta. De acordo com Silva \& Ribeiro (2001), na fase inicial, 1 a 14 dias de idade, as codornas japonesas dobram sete vezes o próprio peso inicial, em função da hipertrofia, principalmente, dos músculos peitorais, do crescimento dos ossos e das vísceras. Com a proximidade da maturidade sexual, o crescimento é fortemente influenciado pela formação das reservas de gordura, especialmente, nas vísceras, no fígado, ovário e oviduto.

Os problemas decorrentes do excesso de consumo de ração em codornas, como obesidade, maturidade sexual precoce, prolapso de oviduto, ovos com gemas múltiplas e reduzida produção de ovos, são semelhantes aos verificados em outras aves comerciais. Assim como os efeitos da desnutrição sobre o atraso da maturidade sexual e a redução do peso corporal, do nível das reservas corporais, do pico e da persistência de postura, levam ao descarte e à reposição do plantel mais cedo (Silva, 2003).

Segundo Chwalibog (1992), citado por Silva (1995), existem dois métodos para se estimarem as exigências nutricionais - o empírico, em que o desempenho do animalé avaliado em função do aumento da concentração de um nutriente na ração, e o fatorial, em que as exigências são estimadas com base na composição corporal do ganho, separando as exigências para mantença e ganho. Segundo Armsby \& Moulton (1925), a mantença é o estado de conservação do status corporal intacto, não existindo perda ou ganho de tecido, nem translocação de matéria no organismo.

Considerando que escassas informações estão disponíveis na literatura mundial sobre as exigências de mantença e de ganho de codornas, desperta interesse conhecê-las, especialmente, a mantença, por se tratar de um conceito importante para animais em crescimento.

O desenvolvimento de modelos de predição com base na metodologia fatorial ganha importância pela flexibilidade e simplicidade de uso, sendo adequados para manipulação por técnicos de empresas avícolas, que, de posse de um modelo e uma calculadora, podem obter, de forma indireta e rápida, as exigências nutricionais das aves e atualizarem as formulações, sem necessidade de realização de ensaios biológicos e análises de laboratório.

Objetivou-se, com este trabalho, desenvolver equações de predição das exigências diárias de consumo de proteína e de energia de codornas japonesas na fase de 1 a 12 dias, a fim de permitir o desenvolvimento de planos de nutrição mais adequados econômico e biologicamente para a espécie.

\section{Material e Métodos}

O experimento foi desenvolvido no galpão experimental do Campus de Bananeiras da Universidade Federal da Paraíba.

\section{Exigência de mantença em proteína e energia}

Um total de 384 codornas japonesas fêmeas de 1 dia de idade foi pesado e distribuído ao acaso em 24 boxes com área de $1,5 \mathrm{~m}^{2}$. Cada box - com um bebedouro pendular, um comedouro tipo bandeja e piso coberto com cama de maravalha - foi telado para impedir o acesso de pássaros e predadores. As aves receberam luz e aquecimento durante 24 horas, utilizando-se lâmpadas incandescentes de $150 \mathrm{~W}$.

As exigências de mantença das codornas em proteína e energia foram estimadas pela metodologia do abate comparativo. Um grupo-referência de 60 aves no início do experimento e todas as aves restantes das parcelas (abate final) foram pesados, submetidos a jejum de sólidos por 18 horas e hídrico de seis horas, novamente pesados e abatidos por deslocamento cervical, evitando-se as perdas de sangue e de penas, para permitir a avaliação da deposição de nutrientes na carcaça.

As carcaças obtidas foram identificadas, armazenadas em freezer e, após o congelamento, cortadas com faca em pedaços para facilitar a trituração em moinho de carne manual e depois no multiprocessador, para triturar, especialmente, as penas e melhorar a representatividade das amostras a serem analisadas, seguindo metodologia citada por Albino et al. (1994), Silva (1995), Sakomura (1996) e Basaglia et al. (1998).

Amostras das carcaças foram pesadas e colocadas em estufa sob ventilação forçada a $55^{\circ} \mathrm{C}$, por 72 horas, para realização da pré-secagem, e, posteriormente, moídas três vezes consecutivas em moinho de laboratório equipado com peneira de 30 mesh e conduzidas ao laboratório para as determinações analíticas. As composições em proteína e energia foram obtidas conforme metodologias citadas por Silva (1991).

Em seguida, utilizou-se o procedimento descrito por Albino et al. (1994), Silva (1995), Sakomura (1996) e Longo et al. (2001) para determinar a

\section{R. Bras. Zootec., v.33, n.5, p.1209-1219, 2004}


exigência de mantença em proteína e energia, por intermédio da regressão linear do consumo de proteína ou energia em função dos respectivos valores na carcaça. Os interceptos das equações foram utilizados para determinar as exigências de mantença na fase de 1 a 12 dias, e convertidos por peso metabólico, segundo Kim (1995), em que o peso vivo médio $(\mathrm{kg})$ das aves alimentadas à vontade foi elevado à potência de $0,75\left(\mathrm{~kg}^{0,75}\right)$. O acúmulo médio de nutriente na carcaça das aves de cada boxe foi calculado pela diferença entre a quantidade de nutriente total na carcaça no final do período menos a quantidade de nutriente total presente na carcaça do grupo de abate referência.

As eficiências de utilização de proteína ou de energia para ganho foram determinadas pelos coeficientes de regressão de proteína ou de energia retidas em função dos consumos de proteína ou de energia (Baker et al., 1996). Pelo procedimento descrito por Lofgreen \& Garret (1968), a energia líquida para mantença foi estimada pelo logaritmo da produção de calor em jejum, obtida pela extrapolação ao nível zero de ingestão de EMAn. A produção de calor (PC) foi estimada pela diferença entre o consumo de EMAn e a retenção de energia (Chudy, 2000). As exigências líquidas de mantença $\left(\mathrm{EL}_{m}\right)$ foram estimadas pelo antilog do intercepto/ $/ \mathrm{kg}^{0,75}$, da função entre o Log da produção de calor (PC) e o consumo de EMAn. Posteriormente, determinou-se a eficiência de utilização da EM da dieta em $\mathrm{EL}_{m}$ pela relação entre a exigência de $\mathrm{EL}_{m}$ e a exigência de mantença, conforme procedimento descrito por Silva (1995).

Foi utilizado um delineamento inteiramente ao acaso com quatro tratamentos, constituídos pela oferta de ração à vontade, 80,60 e 40\% (próximo à mantença) do consumo à vontade registrado no dia anterior. Cada tratamento tinha seis repetições de 10 aves. A ração foi formulada com $28 \%$ de PB e $2.900 \mathrm{kcal}$ de EMAn/kg (Tabela 1), segundo Leeson \& Summers (1997). Os valores de EMAn determinados para o milho e o farelo de soja por Silva et al. (2003) foram usados no balanceamento da energia da ração do presente ensaio e na determinação do consumo de energia no período.

\section{Exigência de ganho em proteína e energia}

As exigências de proteína e energia para ganho foram determinadas a partir de 180 aves criadas e alimentadas à vontade com a ração experimental (Tabela 1), de acordo com Albino et al. (1994) e Silva (1995).
Seqüencialmente, quatro grupos de 15 codornas, criados paralelamente com alimentação ad libitum, foram abatidos aos 4,8 e 12 dias para estimar as exigências de ganho. Foi determinado o ganho de peso e, posteriormente, o ganho de proteína e de energia na carcaça.

Determinou-se a exigência líquida de proteína ou energia, em função do peso vivo; dividindo-se este valor pela eficiência de utilização da proteína ou energia para ganho, determinou-se a exigência de proteína ou energia dietética. A eficiência de utilização da PB ou da EMAn foi obtida pela regressão entre a proteína ou a energia retida na carcaça, em função dos respectivos consumos (Albino et al., 1994; Silva, 1995; Sakomura, 1996).

A proteína depositada foi quantificada pela porcentagem de proteína na matéria natural do corpo (g). Assim, estimaram-se as exigências líquidas diárias de proteína para o ganho de peso, a partir da regressão linear do teor de proteína corporal (g), em função do peso corporal das aves (g), de acordo com Albino et al. (1994), Silva (1995), Sakomura (1996), Basaglia et al. (1998), Longo et al. (2001) e Sakomura et al. (2002).

Os valores de temperatura e umidade foram anotados diariamente em dois horários $(8$ e $17 \mathrm{~h})$. As médias de temperatura foram de 25,6 e $35,9^{\circ} \mathrm{C}$ e de umidade, de 41,9 e $81,0 \%$, respectivamente, para os valores mínimos e máximos observados.

Equações de predição das exigências de mantença $e$ de ganho em proteína e energia

Considerando-se as exigências diárias de mantença e de ganho de proteína ou energia, foram obtidos modelos de predição das exigências de proteína e de energia para o crescimento de codornas japonesas, na fase de 1 a 12 dias de idade.

As análises estatísticas foram realizadas utilizando o programa SAEG desenvolvido pela Universidade Federal de Viçosa - UFV, versão 5.0 (1982), por intermédio dos procedimentos Regreamd1 e Regrelin.

\section{Resultados e Discussão}

\section{Desempenho das aves e composição corporal}

Na Tabela 2, são apresentados os pesos inicial e final das aves e os consumos de ração, de proteína e de energia. Observa-se redução do peso corporal final e, conseqüentemente, dos consumos de $\mathrm{PB}$ e de $\mathrm{EB}$, à medida que o nível de oferta de ração baixou de 100 para $40 \%$. Reduções semelhantes nos teores de 
Tabela 1 - Composições percentuais, químicas e valor nutricional da dieta experimental, expressos na matéria natural ${ }^{1}$ Table 1 - Proportional and chemical composition and nutritional value of the experimental diet, express as fed

\begin{tabular}{|c|c|c|c|}
\hline \multirow{2}{*}{$\begin{array}{l}\text { Ingrediente } \\
\text { Feedstuff } \\
\text { Milho }\end{array}$} & $\%$ & \multicolumn{2}{|l|}{$\begin{array}{l}\text { Composição química } \\
\text { Chemical composition }\end{array}$} \\
\hline & 36,570 & Proteína bruta $(\%)$ & 28,00 \\
\hline Corn & & Crude protein & \\
\hline Farelo de soja & 54,224 & EMn analisada $(\mathrm{kcal} / \mathrm{kg})^{5}$ & 2.968 \\
\hline Soybean meal & & Analyzed MEn & \\
\hline Calcário & 1,272 & EMn calculada (kcal/kg) & 2.900 \\
\hline Limestone & & Calculated MEn & \\
\hline Fosfato bicálcico & 2,528 & Cálcio & 1,300 \\
\hline Dicalcium phosphate & & Calcium & \\
\hline DL-metionina & 0,187 & Fósforo disponível & 0,600 \\
\hline DL-methionine & & Available phosphorus & \\
\hline L-lisina $\bullet \mathrm{HCl}$ & 0,065 & Metionina & 0,600 \\
\hline$L-L y s \bullet H C l$ & & Methionine & \\
\hline Óleo de soja & 4,562 & Metionina + cistina & 1,009 \\
\hline Vegetable oil & & Methionine plus cystine & \\
\hline Sal comum & 0,332 & Lisina & 1,650 \\
\hline Salt & & Lysine & \\
\hline Cloreto de colina & 0,100 & Treonina & 1,086 \\
\hline Choline chroline & & Threonine & \\
\hline Premix vitamínico ${ }^{2}$ & 0,100 & Triptofano & 0,374 \\
\hline Vitamin premix & & Tryptophan & \\
\hline Premix mineral $^{3}$ & 0,050 & Valina & 1,301 \\
\hline Mineral premix & & Valine & \\
\hline $\mathrm{BHT}^{4}$ & 0,010 & Sódio & 0,180 \\
\hline Total & 100,000 & Sodium & \\
\hline $\begin{array}{l}{ }^{1} \text { Recomendações seg } \\
{ }^{1} \text { Nutritional recommenda } \\
{ }^{2} \text { Composição/kg do pro } \\
\text { Vit. } \mathrm{B}_{6}-3.000 \mathrm{mg} \text {; Ác } \\
3.500 \mathrm{mg} ; \text { Ácido nico } \\
{ }^{3} \text { Composição/kg do pro } \\
-1000 \text { g. } \\
{ }^{4} \mathrm{BHT}=\text { Butil-Hidróxi-To } \\
{ }^{5} \text { Considerando os val } \\
{ }^{5} \text { Based on the energy va }\end{array}$ & $\begin{array}{l}\text { ers (1997) } \\
\text { ers (1997). } \\
\text { roduct): Vit. } \\
\text { tenic acid) } \\
0.000 \mathrm{mg} \text {; } \\
\text { oroduct): M }\end{array}$ & 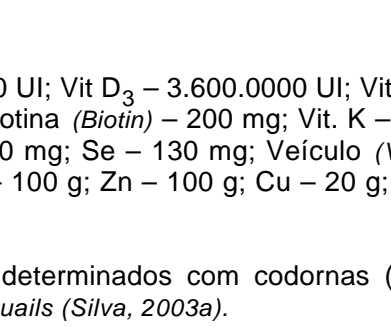 & $\begin{array}{l}\text { /it. } \mathrm{B}_{2}-8.000 \mathrm{mg} \text {, } \\
\text { fólico (Folic acid) - } \\
000 \mathrm{~g} \text {. } \\
\text { Excepiente q.s.p. }\end{array}$ \\
\hline
\end{tabular}

PB e EB da carcaça também foram observadas por Albino et al. (1994), utilizando sistema semelhante de alimentação de poedeiras leves.

Os consumos de ração, de proteína e de energia metabolizável, nesta fase, foram, em valores quantitativos, cerca de três vezes menores que os verificados na fase de 15 a 32 dias (Silva et al., 2004).

$\mathrm{Na}$ Tabela 3, observa-se que as codornas apresentaram composição média em matéria seca, umidade, proteína e energia semelhante àquela das frangas de postura (Albino et al., 1994). A porcentagem de proteína foi semelhante à apresentada por Rabello et al. (2002), para matrizes pesadas (média de 19\%).

A carcaça das codornas nesta fase apresentou menores teores de matéria seca $(26,4 v s .30,9 \%)$, de proteína $(19,9$ vs. $21,2 \%)$ e de energia bruta $(1349 v s$.
$1651 \mathrm{kcal})$ e maiores de água $(73,6 v s .69,0 \%)$ que a carcaça das codornas de 15 a 32 dias de idade (Silva et al., 2004). Redução semelhante, com o envelhecimento de codornas, também foi observada por Marks (1993).

A maior concentração de gordura, que tem mais matéria seca e menos água, na carcaça das aves de 15 a 32 dias é a melhor explicação para estes resultados. Marks (1993) também comentou que as porcentagens de água e de gordura na carcaça de codornas apresentam comportamento inversamente proporcional, em função da idade da ave.

O ganho de peso e as retenções de proteína e de energia na carcaça das codornas de 1 a 12 dias de idade encontram-se na Tabela 4. Decréscimo no ganho de peso das aves, com a redução do nível de oferta de ração de 100 para $40 \%$, refletiu diretamente 
nos declínios das retenções de proteína e de energia na carcaça.

A taxa de retenção de proteína na carcaça das codornas (g/d) de 1 a 12 dias foi levemente menor que a observada por Silva et al. (2004), na fase de 15 a 32 dias $(0,61 v s .0,67 \mathrm{~g} / \mathrm{d})$, entretanto, a taxa de retenção de energia foi muito inferior $(3,75 v s .6,58 \mathrm{kcal} / \mathrm{d})$, sugerindo possível aumento da retenção de gordura, com a aproximação da maturidade sexual das aves, sem afetar substancialmente a retenção de proteína.

Estudos de alometria do crescimento dos componentes do corpo em frangos de corte (Macari et al., 1994), mostraram que o crescimento do tecido magro é maior nas aves jovens, enquanto a taxa relativa de deposição de gordura é maior nas aves mais velhas.

\section{Exigência de mantença}

Com base no peso médio do lote de aves do tratamento com oferta de ração à vontade, foi determinado o peso metabólico das aves como $0,058[(0,0074+0,0381) \div 2]^{0,75}$, conforme proposto por Kim (1995).

A exigência de mantença de $2,845 \mathrm{~g}$ de

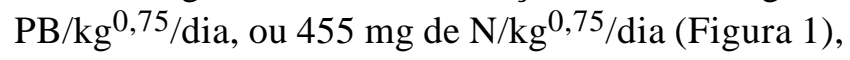

foi inferior à estimada por Macleod (1990), para matrizes em crescimento $(900$ e $1100 \mathrm{mg}$ de $\mathrm{N} / \mathrm{kg}^{0,75} / \mathrm{dia}$ ), e por Albino et al. (1994), para frangas

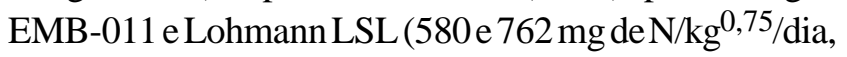
respectivamente), usando a mesma técnica do abate comparativo. Ao contrário, Basaglia et al. (1998), com base no balanço de nitrogênio, observaram menor exigência de mantença em frangas de 1 a 18 semanas de idade $\left(383 \mathrm{mg}\right.$ de $\left.\mathrm{N} / \mathrm{kg}^{0,75} / \mathrm{dia}\right)$. Os resultados parecem sugerir que as espécies apresentam diferentes exigências de mantença e as metodologias experimentais usadas para quantificar a mantença influenciam as estimativas, assim como os sistemas de alojamentos utilizados, tornando-se difícil inferir se as codornas apresentam exigências de mantença maiores ou menor que as poedeiras comerciais.

A exigência de mantença de codornas nesta fase também foi inferior à observada na fase de 15 a 32 dias de idade, de $760 \mathrm{mg}$ de N/kg0,75/dia (Silva et al., 2004). Este resultado sugere que as exigências de PB ou de $\mathrm{N}$ para mantença variam com a idade das aves, tornando válido o fracionamento da exigência de mantença para codornas por fase de crescimento.

Tabela 2 - Peso vivo inicial (PVI) e final (PVF), consumo de ração (CR), consumo de proteína bruta (CP) e consumo de energia metabolizável (CE) e respectivos desvios padrão, em função do nível de oferta (NO) de ração

Table 2 - Starter (SLW) and final live weight (FLW), feed intake (FI), crude protein intake (CPI) and metabolizable energy intake (MEI) and respective standard deviation, in function of the dietary level offer (LO)

\begin{tabular}{cccccc}
\hline NO $(\%)$ & PVI $(\mathrm{g})$ & PVF $(\mathrm{g})$ & $\mathrm{CR}(\mathrm{g} / \mathrm{d})$ & $\mathrm{CP}(\mathrm{g} / \mathrm{d})$ & $\mathrm{CE}(\mathrm{kcal} / \mathrm{d})$ \\
$L O$ & $S L W$ & $F L W$ & $F I$ & $C P I$ & $M E I$ \\
\hline 100 & $7,74 \pm 0,09$ & $38,11 \pm 1,22$ & $5,82 \pm 0,44$ & $1,66 \pm 0,12$ & $17,30 \pm 1,31$ \\
80 & $7,71 \pm 0,07$ & $26,38 \pm 0,74$ & $3,69 \pm 0,09$ & $1,05 \pm 0,03$ & $10,98 \pm 0,29$ \\
60 & $7,67 \pm 0,07$ & $20,82 \pm 0,65$ & $2,76 \pm 0,04$ & $0,78 \pm 0,01$ & $8,18 \pm 0,13$ \\
40 & $7,67 \pm 0,08$ & $14,66 \pm 1,42$ & $1,86 \pm 0,02$ & $0,53 \pm 0,01$ & $5,54 \pm 0,07$ \\
\hline
\end{tabular}

Tabela 3 - Teores de matéria seca (MS), água, proteína bruta (PB) e energia bruta (EB) da carcaça de codornas, em função do nível de oferta (NO) da ração

Table 3 - Dry matter (DM), water, crude protein (CP) and gross energy (GE) contents of quail carcass, in function of the dietary level offer (LO)

\begin{tabular}{ccccc}
\hline NO & MS $(\%)$ & Água $(\%)$ & PB $(\%)$ & EB $(\mathrm{kcal} / \mathrm{kg})$ \\
$L O$ & $D M$ & Water & $C P$ & $G E$ \\
\hline $100 \%$ & $26,40 \pm 0,48$ & $73,60 \pm 0,48$ & $19,93 \pm 0,81$ & $1.349 \pm 0,056$ \\
$80 \%$ & $22,94 \pm 0,34$ & $77,06 \pm 0,34$ & $19,38 \pm 0,33$ & $1.173 \pm 0,013$ \\
$60 \%$ & $24,16 \pm 0,57$ & $75,84 \pm 0,57$ & $18,63 \pm 0,49$ & $1.159 \pm 0,070$ \\
$40 \%$ & $21,65 \pm 1,40$ & $78,35 \pm 1,40$ & $18,41 \pm 1,15$ & $1.031 \pm 0,090$ \\
\hline
\end{tabular}

R. Bras. Zootec., v.33, n.5, p.1209-1219, 2004 
O logaritmo da produção de calor, em função do consumo de $\mathrm{EMA}_{n}$ (Figura 2), conforme a equação $\log \mathrm{PC}=0,552359+0,0344801 \mathrm{X}\left(\mathrm{r}^{2}=0,97\right)$, resultou em exigência líquida de mantença $\left(\mathrm{EL}_{m}\right)$ de $61,51 \mathrm{kcal} / \mathrm{kg}^{0,75} / \mathrm{dia}$, com eficiência de utilização da $\mathrm{EM}$ da dieta em $\mathrm{EL}_{m}$ de $86 \%$. Este valor é maior que os $65 \%$ obtidos por Silva et al. (2004), em codornas de 15 a 32 dias, e os $72 \%$ verificados por Silva (1995), em frangas.

A produção média de calor de $20,33 \mathrm{kcal} / \mathrm{dia}$, quando a ração foi fornecida à vontade, resultou em $350 \mathrm{kcal} / \mathrm{kg}^{0,75} / \mathrm{dia}$, maior que os $236 \mathrm{kcal} / \mathrm{kg}^{0,75} / \mathrm{dia}$ observados por Silva et al. (2004), em codornas de 15 a 32 dias de idade. Maeda et al. (1994), trabalhando com codornas de sexo misto em crescimento, sugeriram produção de calor de $277 \mathrm{kcal} / \mathrm{kg}^{0,75} /$ dia. Segundo Macleod \& Dabhuta (1997), as codornas apresentam elevada perda de calor metabólico, por apresentar relação superfície: volume favorável.

A exigência de mantença de $77,07 \mathrm{kcal} / \mathrm{kg}^{0,75} / \mathrm{dia}$ (Figura 3) foi menor que a observada por Albino et al. (1994), de 142 e $164 \mathrm{kcal}$, respectivamente, para frangas das linhagens leves EMB-011 e Lohmann LSL, porém é semelhante àquela determinada por Silva et al. (1997), em frangas de 7 a 12 semanas de idade $\left(71,24 \mathrm{kcal} / \mathrm{kg}^{0,75} / \mathrm{dia}\right)$.

A exigência de mantença nesta fase foi $16 \%$ inferior a constatada para a fase de 15 a 32 dias por Silva et al. (2004) de $91,48 \mathrm{kcal} / \mathrm{kg}^{0,75} / \mathrm{dia}$.

Tabela 4 - Ganho de peso (GP), retenção de proteína $(\mathrm{RP})$ e retenção de energia metabolizável (RE) na carcaça de codornas, em função do nível de oferta (NO) da ração

Table 4 - Weight gain (WG), crude protein retention (PR) and $M E$ retention (MER) in quail carcass, in function of the dietary level offer (LO)

\begin{tabular}{cccc}
\hline $\mathrm{NO}$ & $\mathrm{GP}(\mathrm{g} / \mathrm{d})$ & $\mathrm{RP}(\mathrm{g} / \mathrm{d})$ & $\mathrm{RE}(\mathrm{kcal} / \mathrm{d})$ \\
$L O$ & $(W G)$ & $(P R)$ & $M E R$ \\
\hline $100 \%$ & $2,76 \pm 0,23$ & $0,61 \pm 0,06$ & $3,75 \pm 0,41$ \\
$80 \%$ & $1,70 \pm 0,08$ & $0,36 \pm 0,01$ & $1,75 \pm 0,07$ \\
$60 \%$ & $1,20 \pm 0,07$ & $0,26 \pm 0,02$ & $1,16 \pm 0,17$ \\
$40 \%$ & $0,64 \pm 0,13$ & $0,15 \pm 0,01$ & $0,35 \pm 0,12$ \\
\hline
\end{tabular}

R. Bras. Zootec., v.33, n.5, p.1209-1219, 2004

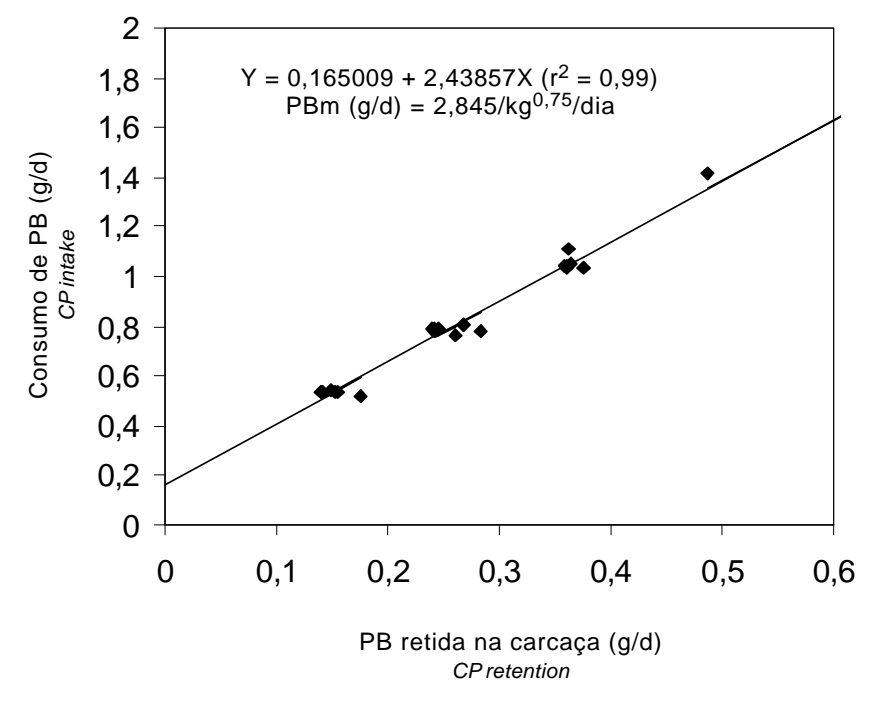

Figura 1 - Relação entre a retenção de proteína bruta (PB) na carcaça de codornas de 1 a 12 dias e o consumo de $P B$, em que a exigência de $\mathrm{PB}$ para mantença $(\mathrm{PBm})$ foi de $2,845 \mathrm{~g} /$ $\mathrm{kg}^{0,75} /$ dia.

Figure 1 - Crude protein of Japanese quails carcass retention and crude protein intake ratio from 1 to 12 days old, where the requirements of maintenance $C P$ was $2.845 / \mathrm{kg}^{7} 75 /$ day.

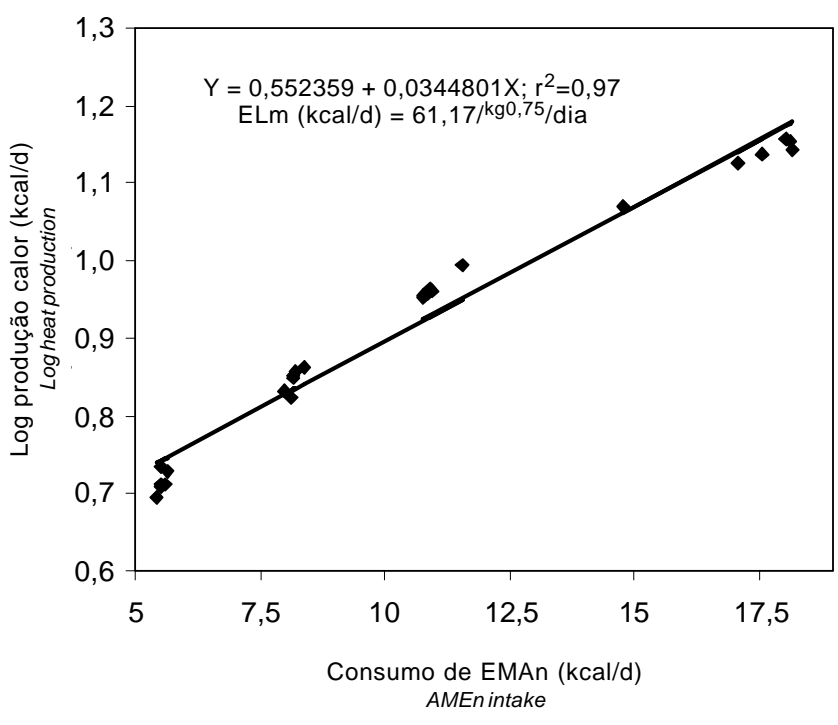

Figura 2 - Relação entre produção de calor e ingestão de EMAn no período de 15 a 32 dias de idade, em que a energia líquida para mantença foi de $59,15 \mathrm{kcal} / \mathrm{kg}^{0,75} / \mathrm{dia}$.

Figure 2 - Relationship between heat production and AMEn intake of Japanese quails from 15 to 32 days of age, where maintenance net energy was of $59.15 \mathrm{kcal} / \mathrm{kg} .75 / \mathrm{day}$. 
Eficiência de utilização de proteína e de energia para ganho

As eficiências de utilização de proteína e energia foram obtidas a partir das equações de regressões dos consumos de proteína e de energia, em função dos respectivos valores na carcaça (Figuras 4 e 5).

A proteína foi retida na proporção de $40 \%$ da proteína ingerida, sendo inferior àquelas das linhagens EMB-011 de 57\% e Lohmann de 62\%, observadas por Albino et al. (1994). Esta eficiência de retenção na carcaça da proteína ingerida foi maior que a observada de $23 \%$, para as codornas na fase de 15 a 32 dias de idade (Silva et al., 2004). O resultado da eficiência de retenção da proteína sugere que em torno de $60 \%$ da proteína ingerida são perdidos ou oxidados.

O intercepto da equação de regressão linear da retenção de proteína corporal, em função do consumo de proteína (Figura 4), possibilitou a estimativa da proteína endógena em $1,1 \mathrm{~g} / \mathrm{kg}^{0,75} / \mathrm{dia}$ ou do nitrogênio endógeno em $176 \mathrm{mg} / \mathrm{kg}^{0,75} / \mathrm{dia}$. Esta última estimativa concorda com a descrita por Shim \& Vohra (1984), para codornas (de $201 \mathrm{mg}$ de $\mathrm{N} / \mathrm{kg}^{0,75} /$ dia), porém é inferior à estimada por Albino et al. (1994), para

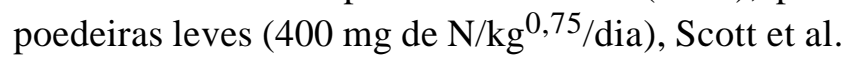

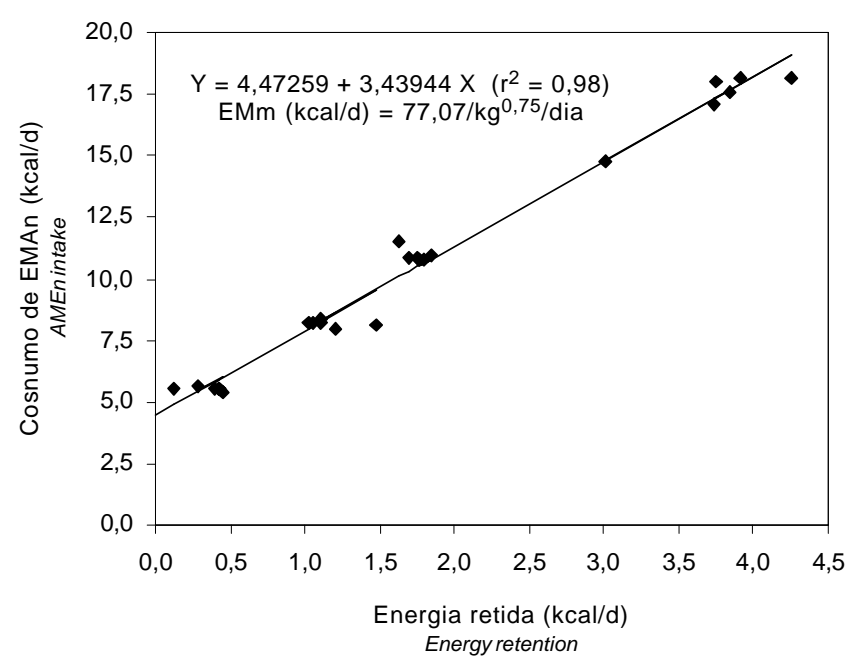

Figura 3 - Relação entre a retenção de energia na carcaça de codornas de 1 a 12 dias e o consumo de energia metabolizável (CEM), em que a exigência de $E M$ para mantença $\left(E M_{m}\right)$ foi de $77,07 \mathrm{kcal} / \mathrm{kg}^{0,75} / \mathrm{dia}$.

Figure 3 - Energy carcass retention and metabolizable energy intake ratio of Japanese quails from 1 to 12 days old, where the requirements of maintenance energy is $77.07 \mathrm{kcal} / \mathrm{kg} .75 /$ day.
(1982), para aves em geral $\left(250 \mathrm{mg} / \mathrm{kg}^{0,75} / \mathrm{dia}\right)$, e Basaglia et al. (1998), para frangas leves (258 $\mathrm{mg}$ de $\mathrm{N} / \mathrm{kg}^{0,75} /$ dia).

A EMA corrigida pelo balanço de $\mathrm{N}$ ingerida apresentou eficiência de utilização de $28 \%$, confirmando o resultado observado por Farrel et al. (1982), citados por Shim \& Vohra (1984), em codornas $(33 \%)$, e inferior às observadas por Siregar \& Farrel (1980), em patinhos (62\%) e frangas (50\%), e por Albino et al. (1994), em frangas das linhagens EMB-011 e Lohmann (47 e 55\%, respectivamente).

A eficiência de utilização da energia de $28 \%$ foi superior à obtida por Silva et al. (2004), de 22\%, na fase de 15 a 32 dias, sugerindo que as codornas utilizam melhor a energia ingerida na fase inicial. Este resultado também indica que $72 \%$ da energia ingerida foram perdidos ou oxidados pelo organismo.

Uma possível explicação para a menor eficiência de utilização da EM pelas codornas em relação às frangas pode estar relacionada à elevada perda de calor corporal favorecida pela menor relação superfície: volume corporal das codornas, conforme Macleod \& Dabhuta (1997). Fatores como a baixa densidade utilizada (13 aves $\left./ \mathrm{m}^{2}\right)$ e a criação em piso também podem ter aumentado o gasto de mantença

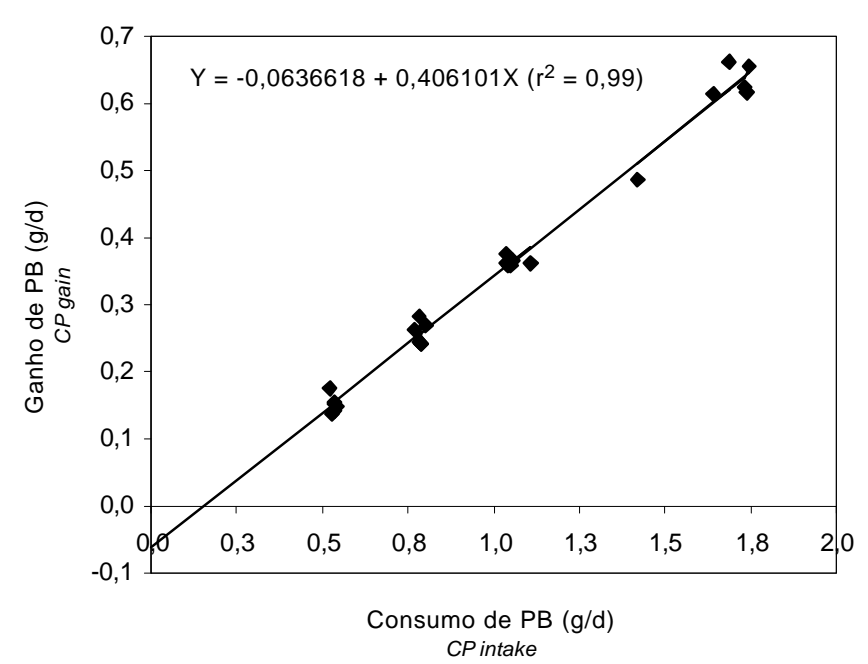

Figura 4 - Proteína retida (PR), em função do consumo de proteína bruta (PB) de codornas na fase de 1 a 12 dias de idade, em que a eficiência de utilização da PB foi de $40 \%$.

Figure 4 - Crude protein carcass retention, in function of crude protein intake of Japanese quails from 1 to 12 days old, where the CP efficiency of utilization was $40 \%$.

R. Bras. Zootec., v.33, n.5, p.1209-1219, 2004 
das codornas com atividades locomotoras, reduzindo a eficiência de utilização de PB e EM, em comparação às frangas (Silva, 1995). No trabalho de Silva (1995), as frangas de 1 a 42 dias foram alojadas em baterias e, depois, até as 18 semanas, em gaiolas metálicas. Sakomura (2001) mostrou, claramente, que o gasto energético de mantença aumenta quando as aves são criadas no piso em relação à criação em gaiolas. Também, a maior taxa de passagem dos alimentos em codornas (Murakami \& Furlan, 2002) e, possivelmente, maior eficiência de aproveitamento dos nutrientes em frangas modernas contribuíram para realçar essas diferenças.

$O$ intercepto da equação de regressão linear da energia retida em função do consumo de energia (Figura 5) permitiu estimar a perda endógena de energia em $21,55 \mathrm{kcal} / \mathrm{kg}^{0,75} / \mathrm{dia}$.

Exigências de proteína e de energia para ganho de peso

As exigências de proteína e de energia para o ganho de peso foram estimadas pelas diferentes taxas de ganho das aves recebendo a ração à vontade nos períodos de 1 a 4,4 a 8 e 8 a 12 dias (Tabela 5).

As equações de regressão linear da proteína corporal retida em função do peso corporal mostraram exigência líquida de proteína por $\mathrm{g}$ de ganho de $0,189 \mathrm{~g}$ (Figura 6). Considerando a eficiência de utilização da proteína para o ganho de $41 \%$, determinou-se a exigência de $0,461 \mathrm{~g}$ ou $461 \mathrm{mg}$ de proteína/g de ganho ou $74 \mathrm{mg}$ de N/g de ganho. Este resultado é semelhante ao descrito por Rabello et al. (2002), em um experimento com matrizes pesadas ( $481 \mathrm{mg}$ de proteína ou $77 \mathrm{mg}$ de N/g ganho).

Quanto à energia, observou-se exigência líquida de 1,30 kcal/g de ganho (Figura 7), que, dividida pela eficiência de utilização da energia para ganho de $28 \%$ resultou em exigência dietética de 4,64 kcal/g de ganho. Silva (1995) obteve 3,53; 5,51 e 6,58 kcal de $\mathrm{EM} / \mathrm{g}$ de ganho para frangas de 1 a 6,7 a 12 e de 13 a 18 semanas, respectivamente.

Com base nos resultados foram obtidas equações de predições das exigências de proteína $[\mathrm{PB}(\mathrm{g} / \mathrm{d})=$ $\left.2,845 . \mathrm{P}^{0,75}+0,461 . \mathrm{G}\right]$ e de energia [EMAn $(\mathrm{kcal} / \mathrm{d})$ $\left.=77,07 \cdot \mathrm{P}^{0,75}+4,64 \cdot \mathrm{G}\right]$, que foram utilizadas para elaborar a Tabela 6.

Assumindo-se diferentes taxas de ganhos de peso das aves entre o peso inicial e o peso observado no

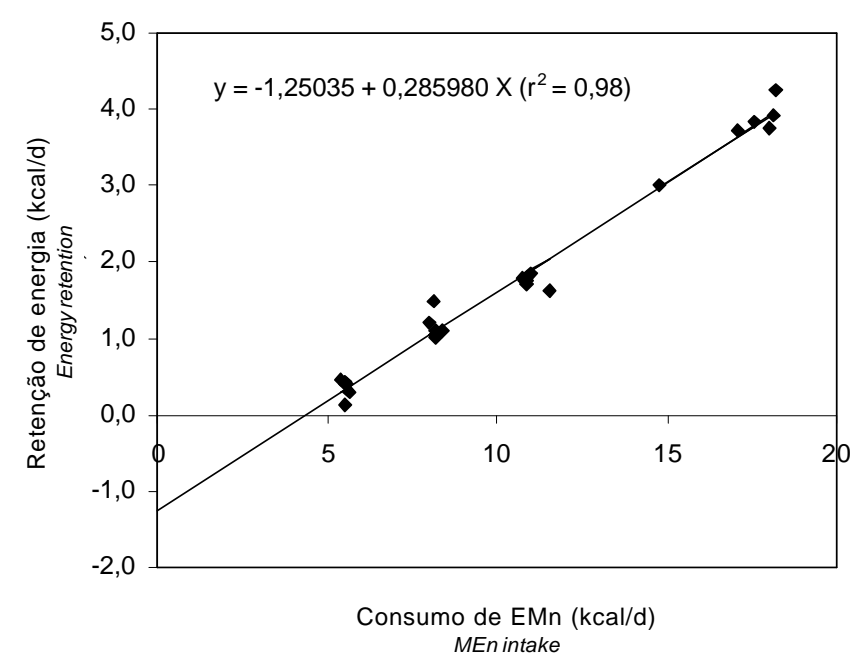

Figura 5 - Energia retida (ER) em função do consumo de EM de codornas na fase de 1 a 12 dias de idade, em que a eficiência de utilização da EM foi de $28 \%$.

Figure 5 - Energy carcass retention in function of ME intake of Japanese quails from 1 to 12 days old, where the ME efficiency of utilization was $28 \%$. 
Tabela 5 - Médias dos valores de peso corporal (PC), porcentagens de matéria seca (MS), água, proteína bruta ( $\mathrm{PBC}$ ), peso da proteína bruta (PB) e energia bruta corporal (EBC) das codornas de 1 a 12 dias de idade

Table 5 - Means of body weight values (BW), dry matter percentage (DM), water, crude protein $(C P)$ and body gross energy (GE) of Japanese quails from 1 to 12 days old

\begin{tabular}{ccccccc}
\hline Idade (dias) & PC & MS & Água & PB $(\%)$ & PB $(\mathrm{g})$ & EB (kcal) \\
Age (days) & $B W$ & $D M$ & Water & $C P$ & $C P$ & $G E$ \\
\hline 1 & 8,34 & 21,85 & 78,15 & 13,88 & 1,16 & 11,99 \\
4 & 9,52 & 19,98 & 80,02 & 15,19 & 1,45 & 9,55 \\
8 & 18,38 & 24,27 & 75,73 & 18,56 & 3,41 & 24,29 \\
12 & 35,31 & 26,39 & 73,61 & 18,46 & 6,52 & 45,10 \\
\hline
\end{tabular}

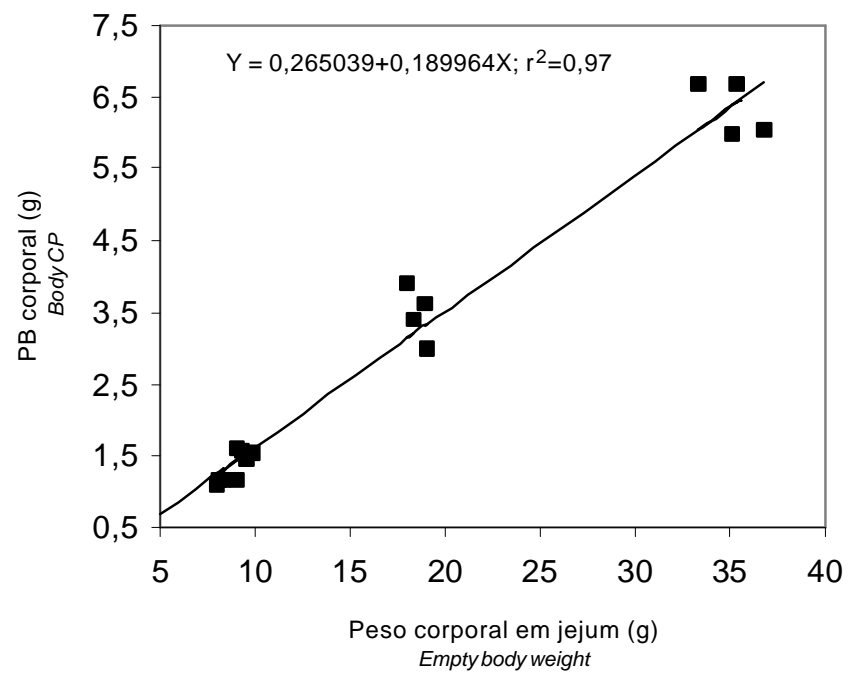

Figura 6 - Relação entre o conteúdo de proteína corporal e o peso corporal das codornas japonesas no período de 1 a 12 dias de idade.

Figure 6 - Body protein content and body weight ratio of Japanese quails from 1 to 12 days old.

final de cada subfase ( 1 a 4,4 a 8 e 8 a 12 dias), determinaram-se as exigências quantitativas de energia ou proteína para mantença e ganho. Quanto maior o ganho de peso desejado, maiores quantidades de ração, de proteína e de energia devem ser fornecidas às aves. Rações com maior densidade energética devem conter mais proteína, em virtude do menor consumo. De 1 a 12 dias, rações com 2.700, 2.800 e $2.900 \mathrm{kcal}$ EMAn devem ter, respectivamente, 22, 23 e 24\% PB, valores semelhantes aos estimados para a fase de 15 a 32 dias (Silva et al., 2004).

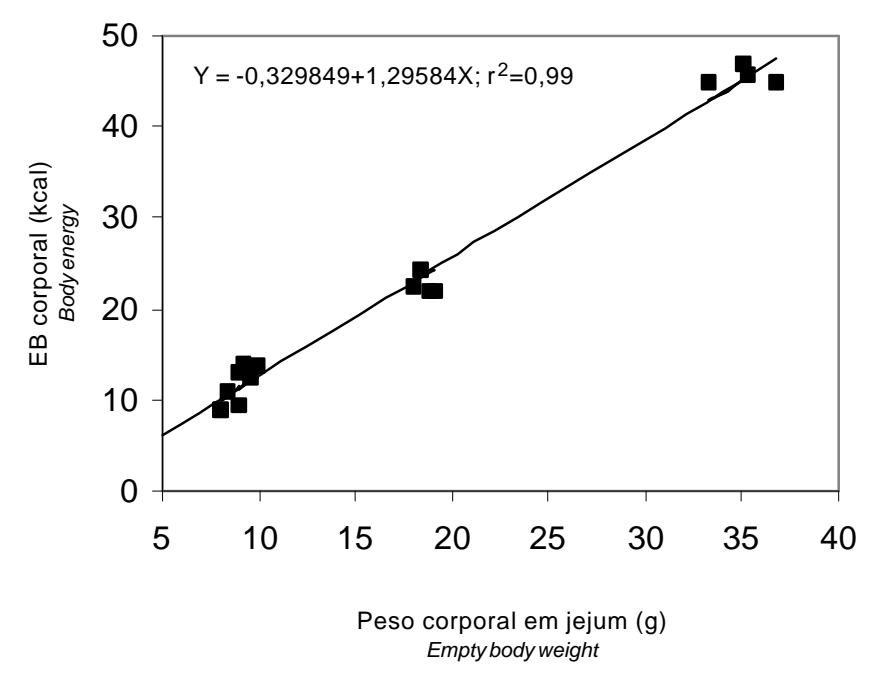

Figura 7 - Relação entre o conteúdo de energia corporal e o peso corporal das codornas japonesas no período de 1 a 12 dias de idade.

Figure 7 - Body energy content and body weight ratio of Japanese quails from 1 to 12 days old.

\section{Conclusões}

As equações de predição para estimar as exigências de mantença e ganho em proteína e energia, em codornas japonesas na fase de 1 a 12 dias, foram: $\mathrm{PB}(\mathrm{g} / \mathrm{ave} / \mathrm{d})=2,845 \cdot \mathrm{P}^{0,75}+0,461 \mathrm{~g}$ $\mathrm{PB} / \mathrm{g}$ de GP e EM $(\mathrm{kcal} / \mathrm{ave} / \mathrm{d})=77,07 \cdot \mathrm{P}^{0,75}+4,64$ $\mathrm{kcal} / \mathrm{g}$ GP, em que PB é a exigência de proteína bruta; PV, o peso vivo (kg); GP, o ganho de peso; e EM, a exigência de energia metabolizável aparente nitrogênio corrigida. 


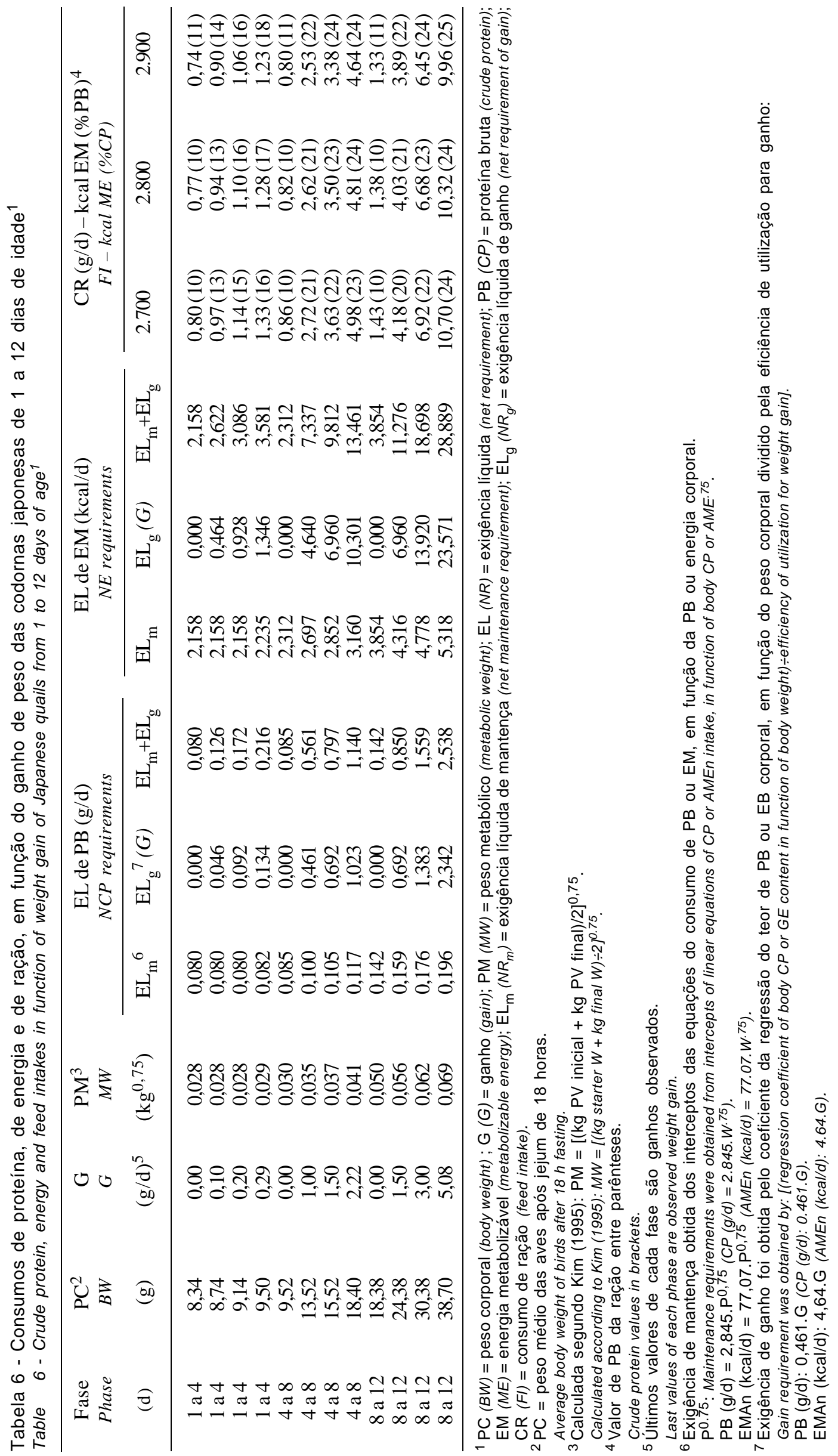

R. Bras. Zootec., v.33, n.5, p.1209-1219, 2004 


\section{Literatura Citada}

ALBINO, L.F.T.; FIALHO, F.B.; BELLAVER, C. et al. Estimativas das exigências de energia e proteína para frangas de postura em recria. Pesquisa Agropecuária Brasileira, v.29, p.1625-1629, 1994.

ARMSBY, H.P.; MOULTON, C.R. The animal as a convertor of matter and energy. New York: Chemical Catalog Co. Inc., 1925.

BAKER, D.H.; FERNANDEZ, S.R.; PARSONS, C.M. et al. Maintenance requirement for valine and efficiency of its use above maintenance for accretion of whole body valine and protein in young chicks. Journal of Nutrition, v.126, p.1844-1851, 1996.

BASAGLIA, R.; SAKOMURA, N.K.; RESENDE, K.T. et al. Exigências de proteína para frangas de postura de 1 a 18 semanas de idade. Revista Brasileira de Zootecnia, v.27, n.3, p.556-563, 1998.

CHENG, K.M. Japanese quail breeding: where are we heading. In: SIMPÓSIO INTERNACIONAL DE COTURNICULTURA, 1., Lavras, 2002. Anais ... Lavras: Universidade Federal de Lavras, 2002. p.133-145.

CHUDY, A. Model for the interpretation of energy metabolism in farm animals. In: McNAMARA, J.P. (Ed.) Modelling nutrient utilization in farm animals. Wallingford: CABI Publishing, 2000. p.329-346.

FARREL, D.J.; ATMANNIHARDJA, S.I.; PYM, R.A.E. Calorimetric measurements of the energy and nitrogen metabolism of Japanese quail. British Poultry Science, v.23, p.375, 1982.

HOFFMANN, E. Breeding quail. In: HOFFMANN, E. (Ed.) Coturnix quail. Nova Scotia: 1988. p.3-11.

KIM, I.K. Maintenance requirements for amino acids by rats. Journal of Nutrition, v.125, p.1367, 1995.

LEESON, S.; SUMMERS, J.D. Commercial poultry nutrition. 2.ed., Guelph: Univ. Books, 1997. 350p.

LOFGREEN, G.P.; GARRETT, W.N. A system for expressing net energy requirements and feed values for growing and finishing beef cattle. Journal of Animal Science, v.27, p.793-806, 1968.

LONGO, F.A.; SAKOMURA, N.K.; FIGUEIREDO, A.N. et al. Equações de predições das exigências protéicas para frangos de corte. Revista Brasileira de Zootecnia, v.30, n.5, p.1521-1530, 2001.

MACARI, M.; FURLAN, R.L.; GONZALES, E. Fisiología aviária aplicada a frangos de corte. Jaboticabal: Universidade Estadual Paulista, 1994. 296p.

MaCLEOD, M.G. Energy and nitrogen intake, expenditure and retention at $20^{\circ}$ in growing fowl given diets with a wide range of energy and protein contents. British Poultry Science, v.64, p.625-637, 1990.

MaCLEOD, M.G.; DABHUTA, L.A. Diet selection by Japanese quail (Coturnix coturnix japonica) in relation to ambient temperature and metabolic rate. British Poultry Science, v.38, p.586-589, 1997.

MAEDA, Y.; KAWABE, K.; OKAMOTO, S. et al. Comparison of energy metabolism during the growing period in quail lines selected for body weight. British Poultry Science, v.35, n.1, p.135-144. 1994.

MARKS, H.L. Carcass composition, feed intake, and feed efficiency following long-term selection for four-week body weight in Japanese quail. Poultry Science, v.72, n.6., p.1005-1011, 1993.

MARTINS, E.N. Perspectivas do melhoramento genético de codornas no Brasil. In: SIMPÓSIO INTERNACIONAL DE
COTURNICUlTURA, 1., 2002, Lavras. Anais ... Lavras: Universidade Federal de Lavras, 2002. p.204-208.

MURAKAMI, A.E.; FURLAN, A.C. Pesquisa na nutrição e alimentação de codornas em postura no Brasil. In: SIMPÓSIO INTERNACIONAL DE COTURNICULTURA, 1., 2002, Lavras. Anais... Lavras: Universidade Federal de Lavras, 2002. p.113-120.

OLIVEIRA, B.L. Manejo racional e produtividade das codornas. In: SIMPÓSIO INTERNACIONAL DE COTURNICULTURA, 1., Lavras, 2002. Anais ... Lavras: Universidade Federal de Lavras, 2002. p.133-145.

RABELLO, C.B.V. Equação de predição da exigência de proteína bruta para aves reprodutoras pesadas na fase de produção. Revista Brasileira de Zootecnia, v.31, n.3, p.1204-1213. 2002.

SAKOMURA, N.K. Exigências nutricionais das aves utilizando o modelo fatorial. In: SIMPÓSIO INTERNACIONAL SOBRE EXIGÊNCIAS NUTRICIONAIS DE AVES E SUÍnOS, 1996, Viçosa, MG. Anais... Viçosa, MG: Universidade Federal de Viçosa, 1996. p. 361-388.

SAKOMURA, N.K. Exigências nutricionais. Revista Avicultura Industrial, n.1089, p.20-31, 2001.

SAKOMURA, N.K.; BASAGLIA, R.; RESENDE, K.T. Modelo para determinar as exigências de proteína para poedeiras. Revista Brasileira de Zootecnia, v.31, n.6, p.2247-2254. 2002.

SCOTT, M.L.; NESHEIM, M.C.; YOUNG, R.J. Nutrition of the chicken. 3.ed. Ithaca: Scott \& Ass., 1982. 562p.

SHIM, K.F.; VOHRA, P.A. A review of the nutrition of Japanese quail. World's Poultry Science Journal, v.40, n.3, p.261-274, 1984.

SILVA, R. Exigências de energia metabolizável para frangas de postura de 1 a 18 semanas de idade. Jaboticabal: Universidade Estadual Paulista, 1995. 76p. Dissertação (Mestrado em Zootecnia) - Universidade Estadual Paulista, 1995.

SILVA, D.J. Análises de alimentos (métodos químicos e biológicos). Viçosa, MG: Universidade Federal de Viçosa, 1991. 166p.

SILVA, J.H.V. Tabela nacional de exigências nutricionais de codornas - Composição de alimentos e manejo produtivo. 2.ed. Bananeiras: Universidade Federal da Paraíba, 2003. 45p.

SILVA, J.H.V.; RIBEIRO, M.L.G. Tabela nacional de exigências nutricionais de codornas. 1.ed. Bananeiras: Universidade Federal da Paraíba, 2001. 25p.

SILVA, J.H.V.; SILVA, M.B.; SILVA, E.L. et al. Energia metabolizável de ingredientes determinada com codornas japonesas (Coturnix coturnix japonica). Revista Brasileira de Zootecnia, v.32, n.6, p.1912-1916, 2003 (Supl.2).

SILVA, J.H.V.; SILVA, M.B.; JORDÃO FILHO, J. et al. Exigências de mantença e de ganho em proteína e energia em codornas japonesas (Coturnix coturnix japonica) na fase de 15 a 32 dias. Revista Brasileira de Zootecnia, v.33, n.5, p.1209-1219, 2004.

SILVA, R.; SAKOMURA, N.K.; RESENDE, K.T. et al. Exigências de energia para frangas de postura de 1 a 18 semanas de idade. Revista Brasileira de Zootecnia, v.26, n.1, p.111-120. 1997.

SIREGAR, A.P.; FARREL, D.J. A comparison of the energy and nitrogen metabolism of fed ducklings and chickens. British Poultry Science, v.21, p.213, 1980.

UNIVERSIDADE FEDERAL DE VIÇOSA - UFV. Central de processamento de dados - CPD. SAEG - Sistema para análise estatística e genética. Viçosa, MG: 1982. 59p.

Recebido em: 03/02/02 Aceito em: 25/11/03

R. Bras. Zootec., v.33, n.5, p.1209-1219, 2004 